OPEN ACCESS

Edited by:

Clive N. Trueman,

University of Southampton,

United Kingdom

Reviewed by:

Nuno Queiroz,

Centro de Investigação em Biodiversidade e Recursos Genéticos

(CIBIO-InBIO), Portugal Karissa Opal Lear,

Murdoch University, Australia

*Correspondence:

Charlie Huveneers

Charlie.huveneers@flinders.edu.au

Specialty section: This article was submitted to Marine Megafauna, a section of the journal

Frontiers in Marine Science

Received: 19 April 2021

Accepted: 28 June 2021

Published: 31 August 2021

Citation:

Huveneers $C$, Niella Y, Drew M, McAuley R, Butcher P, Peddemors V, Waltrick D, Dowling C, Mountford S, Keay I and Braccini M (2021)

Continental-Scale Network Reveals

Cross-Jurisdictional Movements of Sympatric Sharks With Implications

for Assessment and Management.

Front. Mar. Sci. 8:697175.

doi: 10.3389/fmars.2021.697175

\section{Continental-Scale Network Reveals Cross-Jurisdictional Movements of Sympatric Sharks With Implications for Assessment and Management}

\author{
Charlie Huveneers ${ }^{1 *}$, Yuri Niella ${ }^{2}$, Michael Drew ${ }^{1,3}$, Rory McAuley ${ }^{4}$, Paul Butcher ${ }^{5}$, \\ Victor Peddemors ${ }^{6}$, Daniela Waltrick ${ }^{7}$, Chris Dowling ${ }^{7}$, Silas Mountford ${ }^{7}$, lan Keay and \\ Matias Braccini ${ }^{7}$
}

${ }^{1}$ Southern Shark Ecology Group, College of Science and Engineering, Flinders University, Bedford Park, SA, Australia, ${ }^{2}$ Department of Biological Sciences, Macquarie University, North Ryde, NSW, Australia, ${ }^{3}$ SARDI Aquatic Sciences, West Beach, SA, Australia, ${ }^{4}$ School of Biological Sciences, The University of Western Australia, Crawley, WA, Australia, ${ }^{5}$ New South Wales Department of Primary Industries, National Marine Science Centre, Coffs Harbour, NSW, Australia, ${ }^{6}$ New South Wales Department of Primary Industries, Sydney Institute of Marine Science, Mosman, NSW, Australia, ${ }^{7}$ Western Australian Fisheries and Marine Research Laboratories, Department of Primary Industries and Regional Development, Government of Western Australia, North Beach, WA, Australia

Understanding the movement ecology of marine species and connectivity of populations is required for effective fisheries management. This is especially the case for species with wide-ranging distributions for which movement can span across several jurisdictions with different management regulations. We used the Australian national network of acoustic receivers facilitated by the Integrated Marine Observing System (IMOS) to describe the extent and frequency of movements for two large epipelagic shark species, the bronze whaler (Carcharhinus brachyurus) and dusky shark (Carcharhinus obscurus). A total of 210 sharks (117 bronze whalers and 93 dusky sharks) were tracked for a 10-year period during which $21 \%$ and $9 \%$ of detected bronze whalers and dusky sharks, respectively, moved between Australian states. Bronze whalers showed more variable inter-state movements, mostly between Western Australia and South Australia but also eastwards to New South Wales (NSW). Although no dusky sharks tagged in Western Australia undertook inter-state movements, $\sim 50 \%$ of the sharks tagged in South Australia went to Western Australia. Five of the 14 dusky sharks tagged in NSW (36\%) were detected across different states but remained on the east and southeast coasts (Queensland, NSW, Victoria, and Tasmania). The IMOS receivers also detected six bronze whalers in Ningaloo Reef, representing an extension of the previously known Australian distribution. Our findings highlight the value of collaboration between researchers and the value of national infrastructure, by providing a more accurate understanding of inter-state movements. This new information will allow the development of more adequate population dynamic models for stock assessment and management advice, requiring 
collaboration among state agencies for coordinating research activities, sharing data and resources, and establishing appropriate cross-jurisdictional policies. This is essential to achieve successful management and conservation outcomes for highly migratory species.

Keywords: shark fisheries, acoustic tracking, large-scale movement, dusky shark, bronze whaler, Carcharhinus obscurus, Carcharhinus brachyurus, fisheries management

\section{INTRODUCTION}

Many marine species undertake extensive oceanic and continental-scale movements, which are influenced by a variety of biological and environmental factors, often related to resource needs (e.g., Block et al., 2011; Espinoza et al., 2016). In species exhibiting large-scale movements, local or regional management measures may not provide adequate protection if the species is exploited in other regions. These species are also more likely to move between different jurisdictions, further complicating management and conservation efforts (Heupel et al., 2015). Defining the extent and occurrence of longrange movements is therefore necessary for a comprehensive understanding of a species' spatial ecology and, within a resource management context, for determining the extent of connectivity among stocks and ensuring sustainable resource use (Lascelles et al., 2014). Various approaches have been applied to define movements and connectivity between stocks: genetics (e.g., Junge et al., 2019), body morphology (e.g., Turan, 2004), microchemistry (Izzo et al., 2016; McMillan et al., 2018), parasites (e.g., Barton et al., 2018), and tracking (e.g., Block et al., 2011; Hussey et al., 2015). For fisheries management, there is a need to ensure that stock delineation and connectivity are measured at the same temporal scale at which movements occur, since fisheries management operates at the ecological rather than the evolutionary scale. Genetic methods can struggle to distinguish the degree of connectivity below which separate stock management is required if migration rates are high (Waples et al., 2008), because demographically-independent populations might still be connected genetically over many generations (Ovenden, 2013). Results from tracking studies might therefore be more relevant to fisheries management, in determining whether stocks are demographically-independent units that should be managed separately (Lédée et al., 2021).

There is an increasing number of acoustic tracking networks worldwide, including in North America (Pacific Ocean Shelf Tracking - POST, Florida Acoustic Cooperative Telemetry FACT, Integrated Tracking of Aquatic Animals - iTag), South Africa (Acoustic Tracking Array Platform - ATAP), and Europe (European Tracking Network - ETN), with most of these large-scale arrays being affiliated to the global Ocean Tracking Network (OTN; O’Dor and Stokesbury, 2009). In Australia, the Integrated Marine Observing System (IMOS) Animal Tracking Facility enables large-scale collaborative animal tracking research through the deployment of continental-scale curtains and grids of IMOS-owned acoustic receivers. The IMOS Animal Tracking Facility network is complemented by a large number of independent, project-based, non-IMOS acoustic receivers that are deployed by individual researchers and research teams to address regional research needs. All IMOS data and the voluntarily supplied detections from non-IMOS receivers are hosted by and publicly accessible through the Australian Ocean Data Network (AODN) and the IMOS Animal Tracking database (Hoenner et al., 2018) ${ }^{1}$. These data enable large-scale studies of animal movements (Heupel et al., 2015), the ability to reveal intra-specific differences in movement profiles and site residency of a wide range of species (Brodie et al., 2018), and to determine how changes in human activity impact animal populations during global disruptions such as the COVID-19 pandemic (Huveneers et al., 2021). The IMOS Animal Tracking Facility provides an opportunity to quantify the extent of movement and connectivity of marine species and determine the most suitable spatial scale for stock assessments and management purposes (Lédée et al., 2021).

The bronze whaler Carcharhinus brachyurus and the dusky shark Carcharhinus obscurus are globally distributed species which are commercially and recreationally targeted in many parts of their distributions, as well as being taken with other more productive shark species in mixed-species fisheries (see Rogers et al., 2013a; Bradshaw et al., 2018). Bronze whaler and dusky shark have life history traits that make them highly susceptible to overexploitation (e.g., slow growth, late age-atmaturity) (Romine et al., 2009; Rogers et al., 2013a; Drew et al., 2017). At a global level, both species are of conservation concern, with the bronze whaler listed as Vulnerable by the IUCN Red List due to declining population trends over most of its range (Huveneers et al., 2020) and the dusky shark listed as Endangered due to a global population reduction of $\sim 72 \%$ (Rigby et al., 2019; Pacoureau et al., 2021). In Australia, bronze whaler and dusky sharks are commercially targeted in New South Wales (NSW), South Australia (SA), and Western Australia (WA) (Simpfendorfer, 1999; Macbeth et al., 2009; Rogers et al., 2013a). In NSW, mostly adult dusky sharks are caught by longline fisheries (Macbeth et al., 2009; Pleizier et al., 2015; Barnes et al., 2016). Catches in NSW appear to have declined due to management action and reduced fishing effort in recent years. In SA, there are no species-specific regulations managing commercial catches of bronze whalers and dusky sharks. However, these species are managed under input controls, with measures aimed at limiting fishing effort and mortality of large mature individuals. These include limits on the daily number of hooks that can be set (200 hooks), on leader diameter for longlines $(2 \mathrm{~mm})$, and mesh size restrictions for demersal gill nets $(150 \mathrm{~mm})$. Bronze whalers and dusky sharks (reported

${ }^{1}$ animaltracking.aodn.org.au 
together as whaler sharks) are considered secondary species, with sustainability of the fishery and stock status assessed using performance indicators. Demographic models suggest that current catch levels of bronze whaler are likely to be sustainable, but that population decline could occur if total catches increase (Bradshaw et al., 2018). However, the need to differentiate the two species remains a key uncertainty in estimating current levels of fishing mortality. The status of the SA whaler shark fishery is therefore classified as undefined (Steer et al., 2020). In WA, due to the rapid increase in shark catches between the mid-1970s and 1990s and other sustainability concerns, a range of management measures have been introduced since the early 1990s (limited entry, effort limits, a maximum size limit, state-wide commercial protection of sharks in most non-target fisheries, prohibition of metal trace wire and large hooks, mesh-size limits in target gillnet fisheries, spatial closures, and recreational bag limits) (Braccini et al., 2021). Weight of evidence assessments are conducted on four indicator species every 5 years, including dusky sharks but not bronze whalers. Stock status of dusky sharks is sustainable - recovering with current management arrangements considered suitable to allow the gradual recovery of the breeding stock from historic overfishing (Braccini et al., 2021). However, dusky shark stock assessment only includes WA catches (Braccini et al., 2021).

Genetic studies have suggested large-scale stock segregation of bronze whalers between Australia-New Zealand, South AfricaNamibia, and Peru (Benavides et al., 2011b), and some delineation within Australia between WA and the rest of the Australian population (Junge et al., 2019). Dusky sharks are currently considered to have an eastern and western stock in Australia, with conventional and electronic tracking showing that dusky sharks move between SA and WA (Rogers et al., 2013b), and genetic analyses suggesting restricted gene flow between eastern and western Australia (Geraghty et al., 2014). However, previous and recent genetic analyses have also proposed panmixia within Australia (Ovenden et al., 2009; Benavides et al., 2011a; Junge et al., 2019). The appropriate spatial scale to assess and manage bronze whaler and dusky shark stocks, and the extent of their movements across each species distribution are still unknown.

We investigated the broad-scale movements and levels of connectivity among bronze whalers and dusky sharks in Australian waters between WA, SA, Victoria (VIC), Tasmania (TAS), NSW, and Queensland (QLD), a spatial scale of 7,300 km, using the network of acoustic receivers facilitated through the IMOS Animal Tracking Facility. We also assessed the benefits of the IMOS Animal Tracking Facility by comparing our ability to detect cross-jurisdictional movements using receivers from the IMOS Animal Tracking Facility (IMOS receivers), community-owned receivers (non-IMOS receivers), or a combination of both. The results from this study provide movement information over spatial and temporal scales relevant to fishery management decisions (Crossin et al., 2017) and insights into the importance of having a continental-scale network of acoustic receivers to support the assessment of species with broad movement patterns for effective fisheries management.

\section{MATERIALS AND METHODS}

\section{Shark Tagging and Acoustic Tracking}

Sharks were captured using a variety of standard fishing methods including scientific and commercial longlines (NSW, SA, and WA), single hook droplines (WA), and recreational game fishing (SA). Captured individuals were measured to the nearest $1 \mathrm{~cm}$, sexed, and had a V16 acoustic transmitter surgically implanted using established methods. Transmitters were programmed on a pseudo-random repeat rate of 40-80 s (NSW), 50-110 s (SA), or 70-200 s (WA) resulting in battery life ranging 1982-3650 days. Details about fishing and tagging methods can be found in Barnes et al. (2016) for NSW, Drew et al. (2019) for SA, and Braccini et al. $(2017,2018 a)$ for WA.

We examined the broad-scale movements of dusky sharks and bronze whalers through acoustic tracking and the multiple acoustic receiver arrays combined through the IMOS Animal Tracking Facility. To date over 9,735 acoustic receiver deployments have occurred at 1,757 locations around Australia ranging from $113.6^{\circ} \mathrm{E}$ to $159.3^{\circ} \mathrm{E}$ and $11.8^{\circ} \mathrm{S}$ to $43.1^{\circ} \mathrm{S}$ (Hoenner et al., 2018). Receivers include core IMOS Animal Tracking Facility infrastructure and receiver arrays maintained by independent researchers who contribute data to the IMOS Animal Tracking Facility (Figure 1). While the total number of receivers slightly varied across the 10-year study period (20102020), receivers were constantly deployed at key locations where bronze whalers and dusky sharks were detected throughout the study period. Further details about the receiver array in SA and WA are provided in Drew et al. (2019) and Braccini et al. (2017, 2018a), respectively.

\section{Data Analysis}

The total detection dataset for the two study species was initially filtered to exclude any false detections (Simpfendorfer et al., 2015), identified following the acceptance criteria developed by the manufacturer (Pincock, 2008). All analyses were conducted in the R software (version 4.0.5; R Core Team 2021).

\section{Inter-State Movements, Connectivity, and Seasonality}

For each species, we used a Generalized Linear Model (GLM) to assess the effect of tracking time (i.e., number of days from tagging to the last data download) on the likelihood of detecting inter-state movements. We used a binomial distribution to model the presence/absence of inter-state movements as a function of tracking time.

The frequency and directionality of inter-state movements was assessed using connectivity plots. For each shark that undertook at least one inter-state movement, each movement was categorized according to the outgoing (i.e., the last state where a shark was detected previously) and incoming (i.e., the next state where a shark was consecutively detected) nature of the movement. A movement matrix was then created for each species, in which the respective total number of individuals moving from/to each state was included. A circular connectivity 

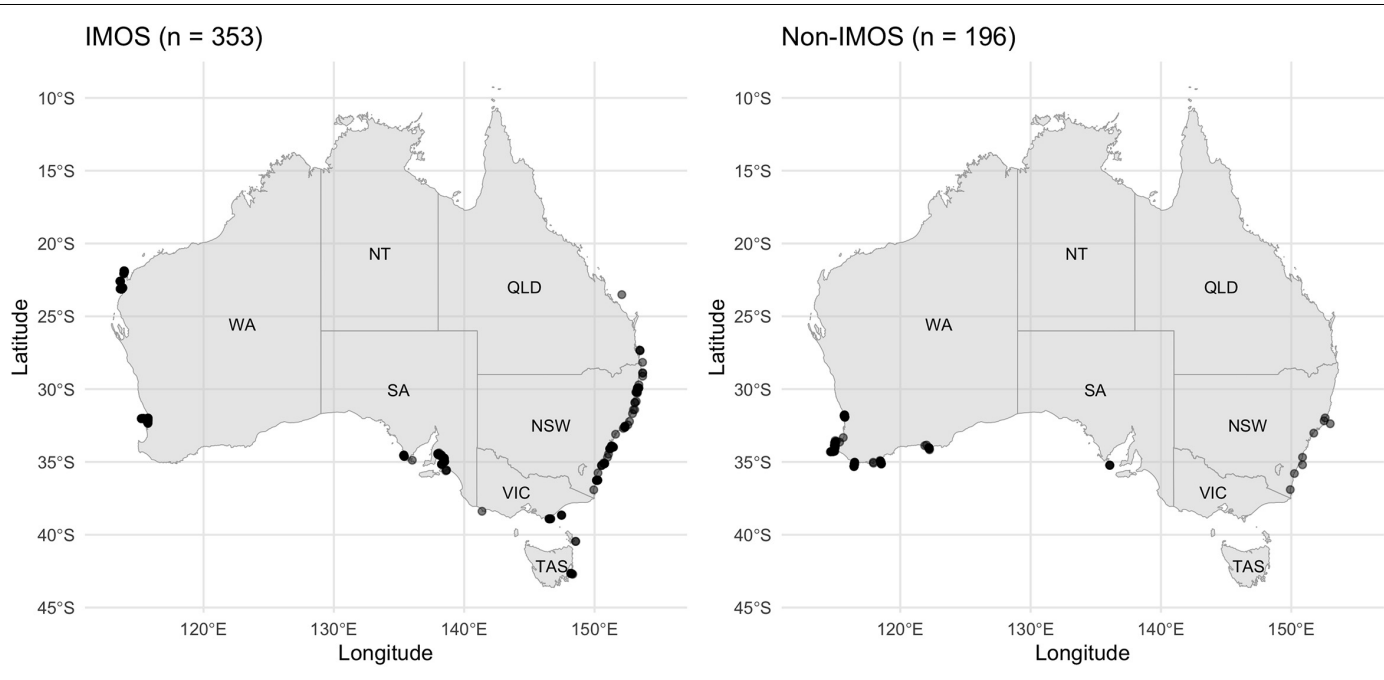

FIGURE 1 | Map of Australia showing the location of (left) Integrated Marine Observing System (IMOS) receivers and (right) non-IMOS receivers that detected bronze whalers and dusky sharks during the study period.

plot was then used to illustrate the shark species-specific interstate movements using the circlize R package (Gu et al., 2014).

For each detected individual, the proportion of time spent in each state was calculated by reconstructing trajectories assuming straight line movement between detections. For this, the position between consecutive detections from different receivers was interpolated (avoiding crossing over land) and the amount of time spent between these detections was split proportionally to the distance between the receivers.

Seasonality of inter-state movement was assessed by modeling changes in detection longitude across months, as spatial variation in the study area was mostly longitudinal. The acoustic detection dataset was first standardized to include only a unique daily location per individual, to avoid biases from sharks repeatedly detected by one receiver in a day and to account for differences in detection range between receivers (Huveneers et al., 2016). Generalized Additive Mixed Models (GAMM) were then built for each species using the mgcv $\mathrm{R}$ package (Wood and Wood, 2015), including location longitudes as the response variables with Gamma distributions. Model candidate predictors included month as a continuous variable ranging from 1 (January) to 12 (December) with a cyclic-cubic regression spline, and the dimensions of the basis used for the smoothing term $(\mathrm{k})$ kept to a value of five to avoid model overfitting. Shark ID was included as a random effect to account for inter-individual variation. Year was not tested as a candidate variable in the models as most sharks from both species were tracked for a small number of years. The effects of size or maturity on movements were not assessed due to the small size ranges of tagged sharks and insufficient numbers of mature sharks. Final models (Longitude $\sim$ Month + Shark ID) were visually inspected for a normal residual distribution.

\section{Benefits of IMOS Animal Tracking Facility}

A randomization test (1,000 random samples simulations) was done to assess the benefits of the IMOS Animal Tracking
Facility, by comparing our ability to detect inter-state movements depending on the group of receivers used: (i) exclusively IMOS receivers, (ii) exclusively non-IMOS receivers, and (iii) combining both receiver types. For each tagged individual, interstate movement was considered to have occurred if the shark was detected for at least 1 day in a different state from where it was tagged. In each iteration, performed with replacement, $50 \%$ of all tagged sharks (i.e., including individuals detected only within the state where they were tagged and those detected also in a different state) were selected randomly for bronze whalers $(N=58)$ and dusky sharks $(N=46)$, and the percentage of individuals moving inter-state calculated. Analysis of variance (ANOVA) and Tukey post hoc tests were used to investigate differences among receiver groups.

\section{RESULTS}

A total of 210 sharks (117 bronze whalers and 93 dusky sharks) were tagged between 31 January 2010 and 19 October 2016 in NSW, SA, and WA (Table 1) and tracked until 5 November 2020. Based on known size-at-maturity (Last and Stevens, 2009; Drew et al., 2017), most tagged bronze whalers (mean \pm standard deviation: $200.9 \pm 86.3 \mathrm{~cm}$ total length) and dusky sharks $(279.9 \pm 60.7 \mathrm{~cm}$ total length) were immature. Similar numbers of bronze whalers were tagged in WA $(51.3 \%$; $N=60)$ and SA (48.7\%; $N=57)$, whereas most dusky sharks were tagged in WA (75.3\%; $N=70$ ) (Table 1). From all sharks tagged, 112 (95.7\%) bronze whalers and 92 (98.9\%) dusky sharks were detected for at least 1 day during the monitoring period. For these sharks, bronze whalers (4,819 $\pm 19,750$ detections/individual) were detected between 3 and 3,127 days (mean $=577.2 \pm 801.6$ days), whereas dusky sharks $(327 \pm 551$ detections/individual) were detected between 1 and 2,730 days (mean $=539.1 \pm 734.9$ days $)$. 
TABLE 1 | Summary of bronze whalers and dusky sharks tagged in Western Australia (WA) and South Australia (SA), and monitored throughout southern Australia.

\begin{tabular}{|c|c|c|c|c|c|c|}
\hline Species & Sex & $\begin{array}{c}\text { Number } \\
\text { tagged in WA }\end{array}$ & $\begin{array}{c}\text { Number } \\
\text { tagged in SA }\end{array}$ & $\begin{array}{c}\text { Number } \\
\text { tagged in NSW }\end{array}$ & $\begin{array}{l}\text { Total length }(\mathrm{cm}) \pm \\
\text { standard deviation }\end{array}$ & $\begin{array}{l}\text { Mean tracking (days) } \pm \\
\text { standard deviation }\end{array}$ \\
\hline \multirow[t]{4}{*}{ Bronze whaler } & Female & 44 & 31 & - & $213.7 \pm 83.3$ & $1227.8 \pm 754.5$ \\
\hline & Male & 16 & 23 & - & $175.5 \pm 54.4$ & $1049.7 \pm 838.3$ \\
\hline & Unknown & - & 3 & - & - & $557.0 \pm 523.4$ \\
\hline & Total & 60 & 57 & - & $200.9 \pm 86.3$ & $1151.5 \pm 783.0$ \\
\hline \multirow[t]{4}{*}{ Dusky shark } & Female & 45 & 4 & 7 & $293.4 \pm 61.3$ & $953.3 \pm 666.7$ \\
\hline & Male & 24 & 5 & 6 & $266.5 \pm 56.1$ & $1247.9 \pm 711.5$ \\
\hline & Unknown & 1 & - & 1 & $246.5 \pm 125.2$ & $1550.4 \pm 1581.8$ \\
\hline & Total & 70 & 9 & 14 & $279.9 \pm 60.7$ & $1075.2 \pm 710.6$ \\
\hline
\end{tabular}

Tracking days represent period between date of tagging and last detection.

\section{A Bronze whaler}

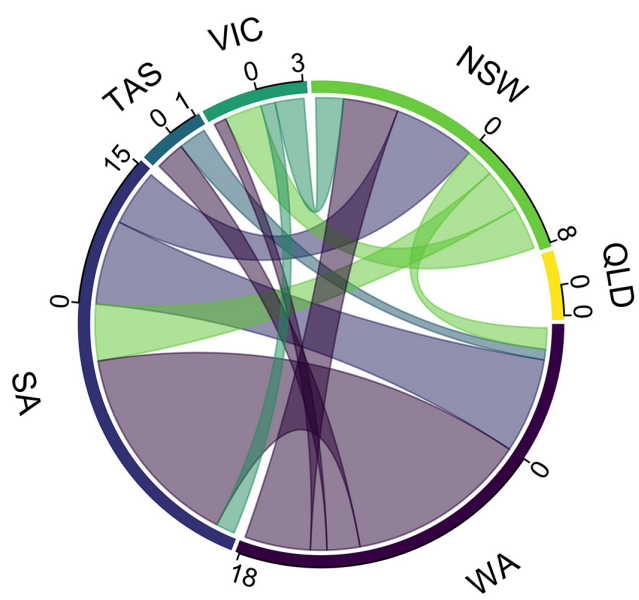

B Dusky shark

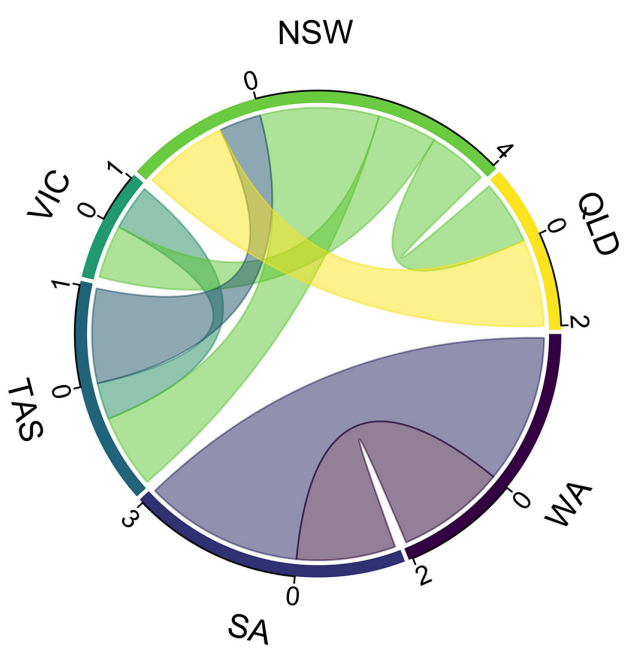

FIGURE 2 | Connectivity plots of (A) bronze whalers and $(\mathbf{B})$ dusky sharks, showing the number and direction of outgoing movements (numbers = observed inter-state movements) from each state (color scale; WA, Western Australia; SA, South Australia; TAS, Tasmania; VIC, Victoria; NSW, New South Wales; and QLD, Queensland).

\section{Inter-State Movements, Connectivity, and Seasonality}

Tracking time had no significant effect on the likelihood of detecting inter-state movements for either dusky sharks (GLM; $p$-value $=0.484)$ or bronze whalers $($ GLM; $p$-value $=0.181)$. Of the 117 bronze whalers and 93 dusky sharks tagged, 25 (21.4\%) bronze whalers (seven tagged in SA and 18 in WA) and eight $(8.6 \%)$ dusky sharks (three tagged in SA and five tagged in NSW) showed inter-state movements. Most of the inter-state movements of the SA-tagged bronze whalers were to the east coast (five out of seven), with only three SA-tagged bronze whalers detected in WA. All but three of the 18 WA-tagged bronze whalers showing inter-state movements were detected in SA, with seven also detected on the east coast (VIC, TAS, NSW; Figure 2A). No Bronze whalers were detected in QLD (Figure 2A). Dusky shark movements were more clearly limited to southwest (SA, WA) and east/southeast (QLD, NSW, VIC, TAS) coasts (Figure 2B). Most bronze whalers tagged in WA spent most of their time within WA, whereas two sharks spent most time in SA and two in NSW (Figure 3A). While most individuals tagged in SA (four) resided in SA, two bronze whalers spent most of their time in NSW, and one spent most of its time in WA (Figure 3A). All SA-tagged dusky sharks spent $>50 \%$ of their time in WA (Figure 3B). For NSW-tagged dusky sharks, five individuals moved inter-state; two moved northwards to QLD and three moved southwards to TAS (Figure 3B).

While the movements of bronze whalers and dusky sharks were influenced by month, there was high inter-individual variation for both species, with Shark ID explaining a great proportion of the deviance (Table 2 ). The relative amount of deviance varied between species, with shark ID explaining more deviance than month for bronze whalers ( 85.2 vs. $3.4 \%$ ), but the opposite occurring in dusky sharks (15.0 vs. $62.5 \%)$. Trends and seasonality of bronze whaler movements across states were not clear, with bronze whalers being detected for most of the year in WA and SA, and across winter, spring, and summer in VIC and NSW (Figure 4A). A slight trend of bronze whalers moving away from WA between February and July was also 

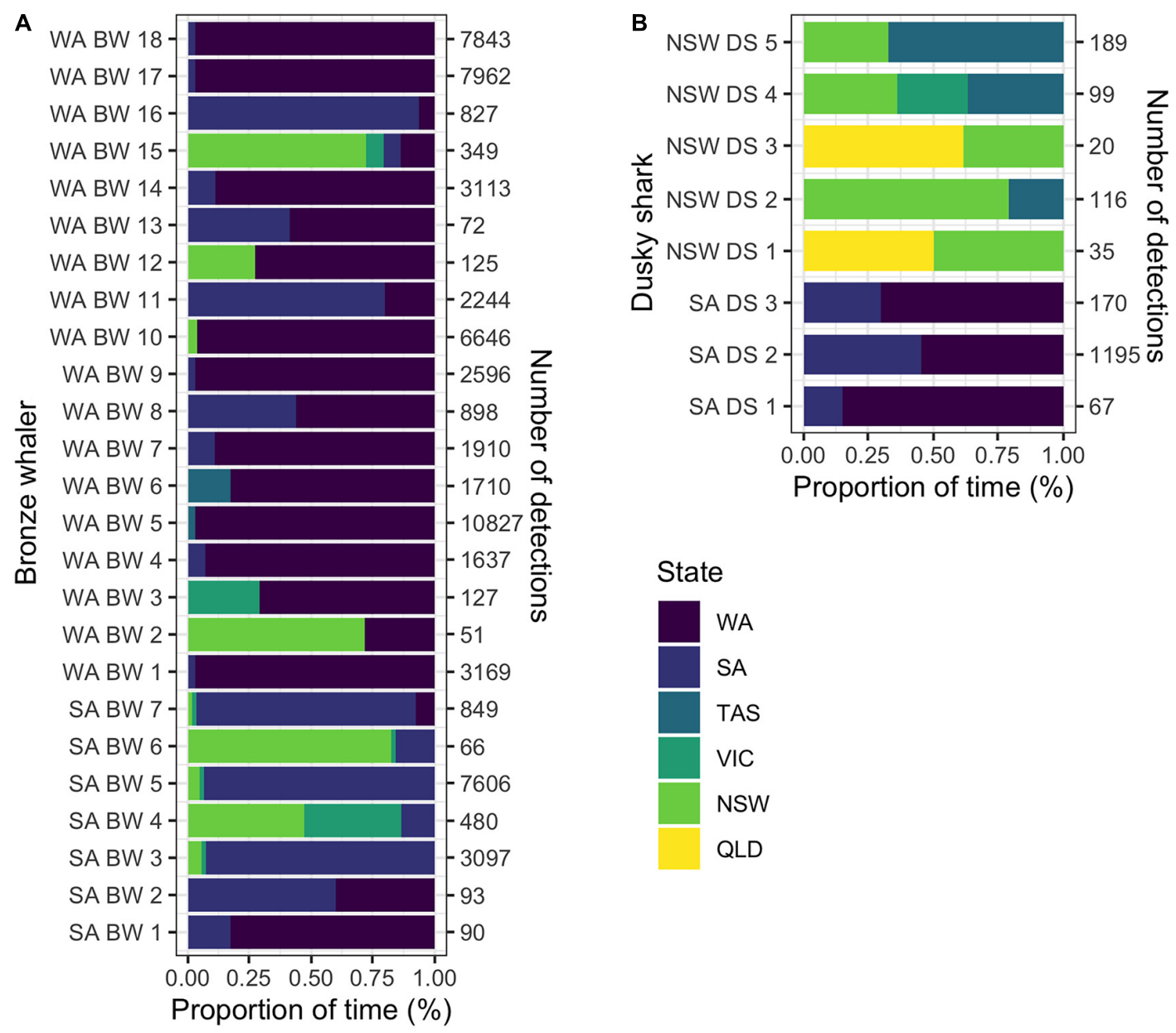

FIGURE 3 | Proportions of time spent by (A) bronze whalers and (B) dusky sharks in each state (color scale: WA, Western Australia; SA, South Australia; VIC, Victoria; and NSW, New South Wales) for the individuals detected at multiple states. Naming legend is composed by the state where the individual was tagged (SA, South Australia; WA, Western Australia), species (BW, bronze whaler; DS, dusky shark) and shark number.

observed (Figure 4A and Table 2). A clearer seasonal trend was observed in the movement patterns of dusky sharks, with individuals tending to move into SA waters during the austral summer (December-February) and into WA in winter-spring (July-October) (Figure 4B and Table 2).

\section{Benefits of IMOS Animal Tracking Facility}

The randomization analysis indicated that the number of random sharks to show inter-state movements varied significantly for bronze whalers $($ ANOVA; $F$-value $=7038, p$-value $<0.001$ ) and dusky sharks (ANOVA; $F$-value $=3010$, $p$-value $<0.001$ ) depending on what receiver group was used. Significantly lower numbers of bronze whalers undertaking inter-state movements were observed with non-IMOS receivers compared to IMOS receivers alone, while higher numbers of sharks were found to move between states when the two receiver types were combined (Figure 5A). For dusky sharks, no inter-state movements were recorded when only non-IMOS receivers were used, whereas the IMOS and all-receiver groups identified similar numbers of sharks moving between states (Figure 5B).

\section{DISCUSSION}

Our study shows that 25 out of 117 tagged bronze whalers (21.4\%) and eight out of 93 tagged dusky sharks (8.6\%) showed interstate movements, with bronze whaler showing more complex and frequent inter-state movements than dusky shark. For bronze whaler, inter-state movements occurred among all five of the southern states, whereas SA- and WA-tagged dusky sharks only moved between WA and SA, and NSW-tagged dusky sharks remained on the east and southeast coasts. While the number of tagged individuals moving among jurisdictions is relatively low, our findings highlight the wide-ranging nature of these two shark species, which needs to be considered in future stock assessments.

For dusky shark, although $8.6 \%$ of all tagged individuals undertook inter-state movements, $\sim 50 \%$ of dusky sharks tagged in SA went to WA. Similarly, a previous study found that all satellite-tracked dusky sharks tagged in SA went to WA (Rogers et al., 2013b). While the number of dusky sharks tagged in SA is small (seven dusky sharks tagged with acoustic tags this study; three dusky sharks tagged with pop-up satellite 
TABLE 2 | Generalized Additive Mixed Models (GAMM) of longitude variation as a function of month for bronze whaler and dusky shark including shark identification number (Shark ID) as random effects.

\begin{tabular}{|c|c|c|c|c|c|c|}
\hline Species & Variable & Edf. & Ref.df. & $F$ & $p$ & Dev.exp. \\
\hline \multirow[t]{2}{*}{ Bronze whaler } & Month & 2.93 & 3.00 & 376725 & $<0.001$ & $3.4 \%$ \\
\hline & Shark ID & 19.97 & 20.00 & 3114 & $<0.001$ & $85.2 \%$ \\
\hline \multirow[t]{2}{*}{ Dusky shark } & Month & 2.66 & 3.00 & 1297 & $<0.001$ & $62.5 \%$ \\
\hline & Shark ID & 1.64 & 2.00 & 6.22 & $<0.001$ & $15.0 \%$ \\
\hline
\end{tabular}

Included are the effective degrees of freedom (Edf.), reference degrees of freedom (Ref.df.), F-statistics (F), $p$-value (p), and percentage of deviance explained (Dev.exp.) of each variable.
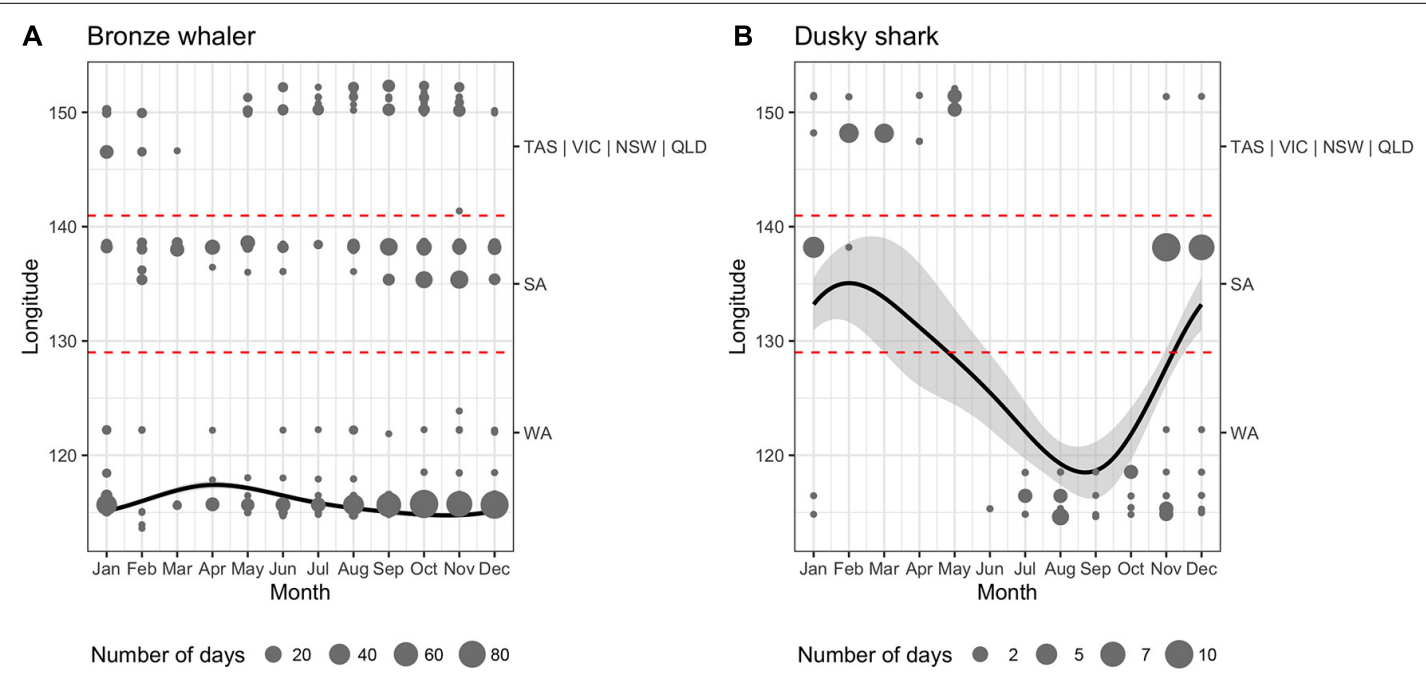

FIGURE 4 | Generalized Additive Mixed Models (GAMM) of longitude variation as a function of month for all tagged (A) bronze whaler and (B) dusky sharks. Shaded areas, points, and dashed lines, respectively, represent the $95 \%$ confidence intervals, the raw location data weighted by the number of days detected in each station (point size), and the longitudinal boundaries between states (WA, Western Australia; SA, South Australia; VIC, Victoria; and NSW, New South Wales).

tags - Rogers et al., 2013b), the high percentage of dusky sharks tagged in SA going to WA [50\% of the ten tagged dusky sharks across Rogers et al. (2013b) and our study] provides evidence of connectivity between the two states. Previous studies reporting movements from conventional tags also show that $3 \%$ of recaptured dusky sharks tagged in WA (2,470 dusky sharks tagged since 1994 and 473 recaptures) were recaptured in SA (Bartes et al., unpublished data). The low percentage of WAtagged dusky sharks moving into SA, higher percentage of SAtagged sharks moving into WA and the species' preference for tropical to warm temperate habitats (Last and Stevens, 2009; Rigby et al., 2019) suggest that dusky shark distribution in this region is likely centered around WA. Small numbers of individuals may occasionally move toward SA when conditions are suitable, such as increased water temperatures during the austral summer (Rogers et al., 2013b). Dusky sharks tagged in NSW showed inter-state movements, but were constrained to eastern Australia, similar to the movements of dusky sharks tagged with pop-up satellite tags in northern NSW (Barnes et al., 2016).

Our findings showing dusky shark movements within, but not between the southwest and east coasts support the separated population structure suggested by Geraghty et al. (2014), with two separated populations in the east and west coasts. These findings challenge the hypothesis of panmixia within Australia proposed by other genetic studies (Ovenden et al., 2009; Benavides et al., 2011a; Junge et al., 2019). While it is possible that some connectivity occurs through northern Australia, this could not be determined in our study due to the limited number of receivers deployed in far north WA and Northern Territory. Bass Strait has previously been identified as a provincial zoogeographic boundary and a region of significant clustering of breaks (Dawson, 2005), with several marine species showing genetic divergences in the vicinity of this region (e.g., white shark, Carcharodon carcharias; Blower et al., 2012; sawsharks, Pristiophorus spp.; Nevatte et al., 2021). Such divergence is likely related to the historical total barrier to gene flow during the late Pliocene, when periods of cold climate and low sealevel segregated warm temperate organisms east or west of the emergent Bassian Isthmus resulting in population divergence and speciation (Waters, 2008). During subsequent periods of warmer and higher seas, sister taxa expanded into the Bass Strait region leading to weakly correlated phylogeographic and biogeographic patterns, with gene flow across Bass Strait hindered by modern oceanographic conditions creating a barrier to dispersal (Dawson, 2005). The panmixia reported in previous studies might have been facilitated by the movements of a small number of individuals (Lowe and Allendorf, 2010) and reflects 

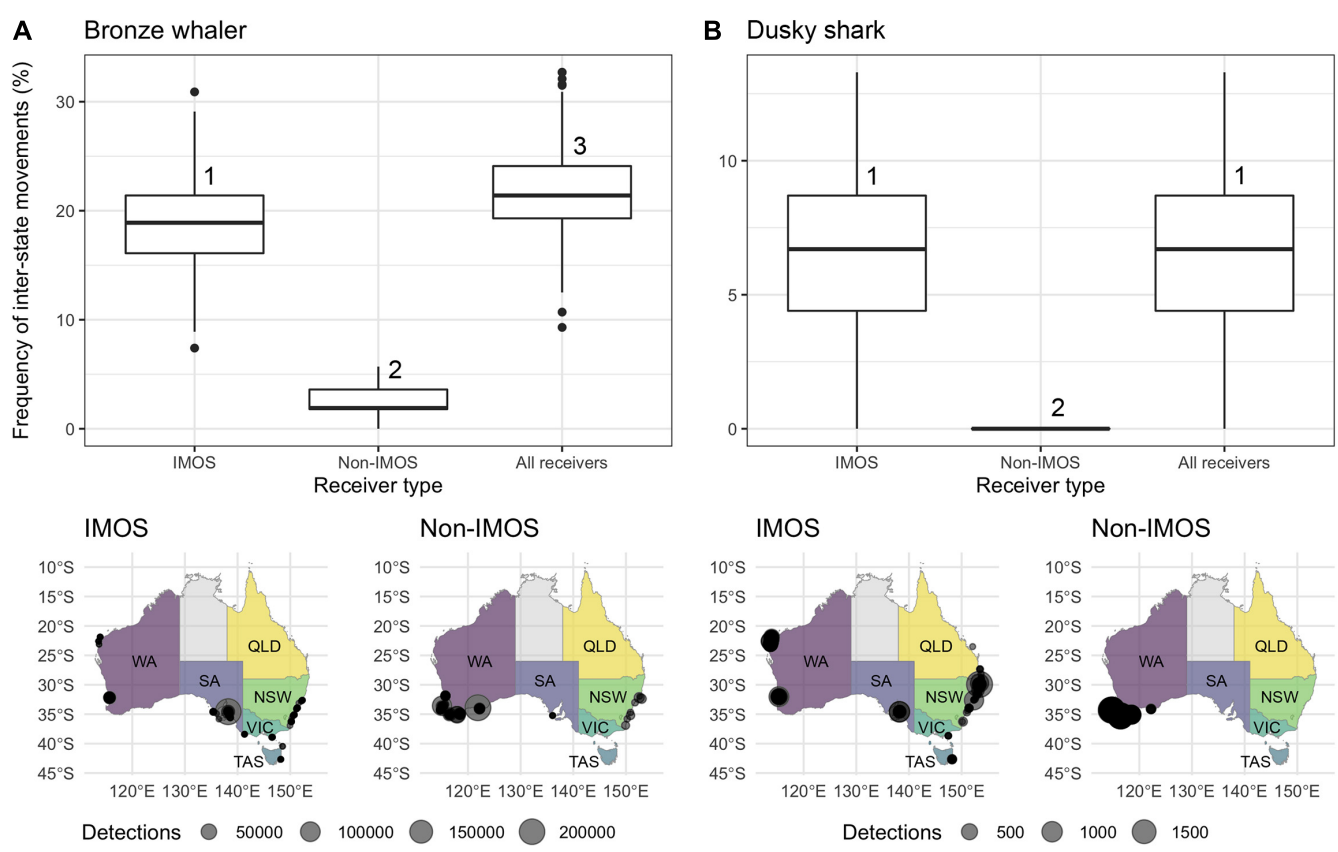

FIGURE 5 | Top panel: Simulation results of frequency distributions of inter-state movements recorded for (A) bronze whalers and (B) dusky sharks using receivers from IMOS, non-IMOS, and a combination of both (All receivers). Numbers above boxes represent the significantly different groups according to the Tukey post hoc test. Bottom panel: Acoustic detections of (A) bronze whalers and (B) dusky sharks by receiver type (IMOS vs. non-IMOS).

the broad connectivity of populations that might occur over multiple generations (i.e., at the evolutionary scale). While this information is valuable for understanding species behavior and evolution, it is less relevant for stock assessment and management advice (Kerr et al., 2016). In situations when genetic analyses suggest panmixia, demographic independence can still occur, leading to discrete stocks that should be modeled and assessed separately (Braccini et al., 2016).

In the case of bronze whalers, acoustic tracking suggests that bronze whalers in southwest Australia represent a single population with complex movements; a WA component that frequents SA and sometimes venture into NSW and a SA component more likely to move eastwards to NSW through VIC. The SA-tagged sharks were also less likely to spend time in WA. This movement from WA and SA to eastern Australia somewhat contrasts with the movement of dusky shark and other large marine predators, i.e., white sharks, where Bass Strait delineates east and west coast stocks. A separation of the WA bronze whalers from the rest of Australia was suggested by Junge et al. (2019), but is not supported by our findings as 18 of the WA-tagged sharks (23\%) moved inter-state, including seven bronze whalers detected in VIC, TAS, and NSW. Overall, bronze whalers show significant connectivity between WA, SA, and NSW. As SA is at the center of the bronze whaler distribution, it is likely playing a central part in this single Australia-wide population.

Seasonal movements varied between species, with dusky sharks showing considerably more defined seasonal interstate movement patterns than bronze whalers. Dusky shark movements matched the previously identified migration westward and across the Great Australian Bight to WA during autumn (Rogers et al., 2013b). In WA, adult dusky sharks occurring north of Perth have a high chance of moving south during the Austral summer, while dusky sharks south of Perth are more likely to move north during the Austral winter (Braccini et al., 2018a). Similarly, dusky shark movements on the east coast support previously reported short-term movements obtained via pop-up satellite tags (Barnes et al., 2016). Large-scale seasonal migrations of dusky sharks are common globally, including in South Africa (Hussey et al., 2009), Western Atlantic Ocean (Kohler et al., 1998; Bangley et al., 2020), and Gulf of Mexico (Hoffmayer et al., 2014). The long battery life of acoustic tags lasting multiple years, however, enabled us to identify consistent occurrence and timing of inter-state movements between SA and WA from individual dusky sharks not previously recorded. Previous studies have also highlighted a strong seasonal occurrence of bronze whalers in inshore waters and migrations likely driven by water temperature and availability of resources (Lucifora et al., 2005; Dudley and Cliff, 2010; Drew et al., 2019). In southern Australia, bronze whalers migrate inside the South Australian gulfs in spring to early autumn (September-April), which coincides with seasonally warm gulf water temperatures (Drew et al., 2019). Additionally, departure from the gulfs in late autumn (May-June) was observed by all bronze whalers tagged with pop-up tags and tracked for more than 60 days (five out of 10 tagged sharks), coinciding with the cooling off gulf and inshore coastal water temperatures (Drew unpublished data). Yet, bronze whalers can be found in the South Australian gulfs throughout winter (Drew et al., 2019), showing that they can withstand the $11^{\circ} \mathrm{C}$ water temperature during mid-winter (July-August) (Petrusevics, 1993). The lack of consistency 
in bronze whaler seasonal migrations between SA and WA observed in this study does not support the seasonal migration of bronze whalers outside the SA gulfs identified previously (Drew et al., 2019). However, the same study also shows that some bronze whalers remain in the gulfs throughout winter, highlighting a considerable degree of individual variation in movement patterns (as shown by Shark ID explaining more deviance than month).

Bronze whalers were previously known to occur throughout southern Australia from Geraldton (WA) across to Coffs Harbour (NSW) (Last and Stevens, 2009; Huveneers et al., 2020). The IMOS receivers detected six bronze whalers in Ningaloo Reef, representing an extension of the known western Australian distribution toward tropical waters and to lower latitudes compared to eastern Australia. While the species is considered to be cosmopolitan in warm temperate and some tropical areas, these detections off Ningaloo Reef are the most northern records of a bronze whaler within tropical waters in Australia.

\section{Implications to Fisheries Management}

The spatial extent of stock assessments should reflect biological population distributions, but this is challenging, particularly for marine species that exhibit large-scale movements such as bronze whaler and dusky shark, as individuals can move over large areas not constrained by jurisdictional boundaries. In Australia, despite fisheries agencies recognizing dusky shark as having two separate populations (eastern and western stocks; Woodhams et al., 2021) and bronze whalers as having one Australia-wide stock (Rogers et al., 2021), both species are assessed and managed as single unit stocks within the jurisdictions of each estate (e.g., Braccini et al., 2018b; Bradshaw et al., 2018; Steer et al., 2020). Evidence generated by our study, together with previously collected genetic and movement information, support that bronze whalers form a single biological stock spanning from WA to NSW, whereas dusky sharks form two biological stocks, a western stock (WASA) and an eastern stock (VIC-NSW). In WA, demographic analysis has identified the need to protect large juveniles and adults from fishing mortality to ensure population persistence (McAuley et al., 2007). Despite harvesting only small juveniles in WA at levels deemed sustainable, unknown sources of mortality in older sharks such as through the SA fishery (Rogers et al., 2013a) may affect abundance and recruitment in WA. Because there are no restrictions on the age- or size-class of sharks that can be fished in SA, it is probable that the SA whaler shark fishery is contributing to overall mortality of the population. Since our findings provide evidence of movements between SA and WA, it is recommended that SA catches of whaler sharks are reported at the species level and that SA dusky shark catch information is shared with WA so that they can be incorporated in future stock assessments. In the case of bronze whalers, while current catch levels are likely to be sustainable, demographic models suggest that population decline could occur if total catches increase (Bradshaw et al., 2018). It is therefore important for all jurisdictions to share information about bronze whaler catches so that any increase in catches can be identified and that the overall stock status can be monitored and assessed. Our study contributes to improving the delineation of the appropriate spatial scale for assessing and managing the bronze whaler and dusky shark stocks in Australia. This information will allow the development of more adequate population dynamic models for stock assessment and management advice, requiring collaboration among state agencies for coordinating research activities, sharing data and resources, and establishing appropriate cross-jurisdictional policies. This is essential to achieve successful management and conservation outcomes for highly migratory species (Lascelles et al., 2014).

\section{Benefits of IMOS Animal Tracking Facility}

The IMOS Animal Tracking Facility enabled a more accurate detection of inter-state movements than receivers deployed by independent research groups in two ways: (1) in the case of dusky shark, the IMOS receivers detected inter-state movements which were not detected by non-IMOS receivers; and (2) in the case of bronze whaler, the use of non-IMOS receivers detected less than half of the inter-state movements compared to both types of receivers combined, underestimating the actual amount of interstate movements. Such discrepancy between receiver types is likely to be a function of the different receiver array designs, their disparate intended purposes, and the relative location of IMOS and non-IMOS receivers in each jurisdiction. IMOS receivers are mostly deployed as cross-shelf curtains designed to record largescale movements (Steckenreuter et al., 2017), while non-IMOS receivers are typically deployed as a grid or specific location targeting a small number of species (except for WA, see McAuley et al., 2017). IMOS receivers also have a broad geographic footprint with the only detections in northern WA, TAS, or QLD being on IMOS receivers. While non-IMOS receivers might also be deployed in these areas, they either did not detect the sharks included in this study or detections were not uploaded to the IMOS database. Overall, this analysis highlights the benefits of the IMOS receiver network and importance of a national database, such as the IMOS Animal Tracking database (Hoenner et al., 2018), in providing animal movement data suitable for development of data-driven management scenarios.

There are inherent limitations to using acoustic tracking and receivers to estimate cross-jurisdictional movements. Acoustic receivers can have variable detection ranges, influenced by a variety of factors including transmitter power output, biofouling, ambient noise, and environmental conditions (Kessel et al., 2014; Huveneers et al., 2016). The ability to detect inter-state movement will also be affected by the acoustic coverage as infrastructure deployments vary in space and time, and logistic limitations can restrict deployments of receivers in remote locations. For example, a small number of receivers were deployed in far north WA and Northern Territory (NT) during the study period, with most of these receivers located in rivers or estuarine environments. This limited the ability to record dusky sharks in the northern part of their distribution.

\section{Conclusion}

Determining the movement patterns of mobile species and identifying stock delineation at the ecological scale rather than evolutionary scale is critical for adequate fisheries management. 
Our findings showed that while a small number of bronze whalers and dusky sharks undertook cross-jurisdictional movements, these are sufficient to refine our understanding of the stock structure of these two species and to challenge some of the previous findings based on genetic analyses. Our study also highlighted the benefit of having a national network of acoustic receivers facilitated by an overarching initiative and revealed that bronze whalers occur further north than previously thought. Further use of the data available through the IMOS Animal Tracking facility will likely enable similar discoveries and will help delineating stock structure in other wide-ranging species (Lédée et al., 2021).

\section{DATA AVAILABILITY STATEMENT}

Publicly available datasets were analyzed in this study. This data can be found here: https://animaltracking.aodn.org.au/.

\section{ETHICS STATEMENT}

The animal study was reviewed and approved by the Flinders University Animal Ethics Committee (ethics approval \#E360) and NSW DPI Animal Care and Ethics Committee (Ref. 12/19).

\section{AUTHOR CONTRIBUTIONS}

$\mathrm{CH}, \mathrm{MD}, \mathrm{RM}$, and $\mathrm{MB}$ conceived the study. $\mathrm{YN}, \mathrm{MB}$, and $\mathrm{CH}$ analyzed the data and wrote the manuscript. All authors

\section{REFERENCES}

Bangley, C. W., Curtis, T. H., Secor, D. H., Latour, R. J., and Ogburn, M. B. (2020). Identifying important juvenile Dusky Shark habitat in the northwest Atlantic Ocean using acoustic telemetry and spatial modeling. Mar. Coastal Fish. 12, 348-363. doi: 10.1002/mcf2.10120

Barnes, C. J., Butcher, P. A., Macbeth, W. G., Mandelman, J. W., Smith, S. D., and Peddemors, V. M. (2016). Movements and mortality of two commercially exploited carcharhinid sharks following longline capture and release off eastern Australia. Endang. Species Res. 30, 193-208. doi: 10.3354/esr00730

Barton, D. P., Taillebois, L., Taylor, J., Crook, D. A., Saunders, T., Hearnden, M., et al. (2018). Stock structure of Lethrinus laticaudis (Lethrinidae) across northern Australia determined using genetics, otolith microchemistry and parasite assemblage composition. Mar. Freshwater Res. 69, 487-501. doi: 10. 1071/mf17087

Benavides, M. T., Horn, R. L., Feldheim, K. A., Shivji, M. S., Clarke, S. C., Wintner, S., et al. (2011a). Global phylogeography of the dusky shark Carcharhinus obscurus: implications for fisheries management and monitoring the shark fin trade. Endang. Species Res. 14, 13-22. doi: 10.3354/esr00337

Benavides, M. T., Feldheim, F., Duffy, C., Wintner, S., Braccini, M., Boomer, J., et al. (2011b). Phylogeography of the copper shark (Carcharhinus brachyurus) in the southern hemisphere: implications for the conservation of a coastal apex predator. Mar. Freshwater Res. 62, 861-869. doi: 10.1071/mf10236

Block, B. A., Jonsen, I. D., Jorgensen, S. J., Winship, A. J., Shaffer, S. A., Bograd, S. J., et al. (2011). Tracking apex marine predator movements in a dynamic ocean. Nature 475, 86-90. doi: 10.1038/nature10082

Blower, D. C., Pandolfi, J. M., Bruce, B. D., Gomez-Cabrera, M. C., and Ovenden, J. R. (2012). Australian white shark population genetics reveals fine scale population structure, transoceanic dispersal events and low effective population sizes. Mar. Ecol. Prog. Series 455, 229-244. doi: 10.3354/meps09659 contributed to the fieldwork and data management, and edited and approved the manuscript.

\section{FUNDING}

Funding was provided through an Australian Research Council Linkage Project grant (LP120100652), the Fisheries Research and Development Corporation (FRDC grant numbers 2010/003, 2010/062, and 2012/020) on behalf of the Australian Government, the Adelaide and Mount Lofty Ranges Natural Resources Management Board, the Neiser Foundation, the Nature Foundation of South Australia Inc., and the Tracking Research for Animal Conservation Society (TRACS). Financial support to YN through an International Macquarie University Research Training Program scholarship is deeply acknowledged.

\section{ACKNOWLEDGMENTS}

The data was sourced from the Ocean Tracking Network project (http://oceantrackingnetwork.org) and from Australia's Integrated Marine Observing System (IMOS) - IMOS is enabled by the National Collaborative Research Infrastructure Strategy (NCRIS). It is operated by a consortium of institutions as an unincorporated joint venture, with the University of Tasmania as Lead Agent. We thank scientists for uploading receiver detections on the IMOS acoustic tracking database, enabling to access detections from these sharks beyond our specific projects.

Braccini, M., Aires-da-Silva, A., and Taylor, I. (2016). Incorporating movement in the modelling of shark and ray population dynamics: approaches and management implications. Rev. Fish Biol. Fish. 26, 13-24. doi: 10.1007/s11160015-9406-x

Braccini, M., de Lestang, S., and McAuley, R. (2018a). Dusky sharks (Carcharhinus obscurus) undertake large-scale migrations between tropical and temperate ecosystems. Can. J. Fish. Aquat. Sci. 75, 1525-1533. doi: 10.1139/cjfas-20170313

Braccini, M., Hesp, A., and Molony, B. (2021). Risk-based weight of evidence assessment of commercial sharks in western Australia. Ocean Coastal Manag. 205:105501. doi: 10.1016/j.ocecoaman.2020.105501

Braccini, M., Johnson, G., Woodhams, J., Rogers, P., and Peddemors, P. (2018b). Dusky shark, Carcharhinus obscurus in Status of Australian Fish Stocks Reports. Canberra: Fisheries Research \& Development Corporation.

Braccini, M., Rensing, K., Langlois, T., and McAuley, R. (2017). Acoustic monitoring reveals the broad-scale movements of commercially important sharks. Mar. Ecol. Prog. Series 577, 121-129. doi: 10.3354/meps 12251

Bradshaw, C., Prowse, T., Drew, M., Gillanders, B., Donnellan, S., and Huveneers, C. (2018). Predicting sustainable shark harvests when stock assessments are lacking. ICES J. Mar. Sci. 75, 1591-1601. doi: 10.1093/icesjms/fsy031

Brodie, S., Lédée, E. J. I., Heupel, M. R., Babcock, R. C., Campbell, H. A., Gledhill, D. C., et al. (2018). Continental-scale animal tracking reveals functional movement classes across marine taxa. Sci. Rep. 8:3717. doi: 10.1038/s41598018-21988-5

Crossin, G. T., Heupel, M. R., Holbrook, C. M., Hussey, N. E., Lowerre-Barbieri, S. K., Nguyen, V. M., et al. (2017). Acoustic telemetry and fisheries management. Ecol. Appl. 27, 1031-1049.

Dawson, M. N. (2005). Incipient speciation of Catostylus mosaicus (Scyphozoa, Rhizostomeae, Catostylidae), comparative phylogeography and biogeography 
in south-east Australia. J. Biogeogr. 32, 515-533. doi: 10.1111/j.1365-2699.2004. 01193.x

Drew, M., Rogers, P., and Huveneers, C. (2017). Slow life-history traits of a neritic predator, the bronze whaler (Carcharhinus brachyurus). Mar. Freshwater Res. 68, 461-472. doi: 10.1071/mf15399

Drew, M., Rogers, P., Lloyd, M., and Huveneers, C. (2019). Seasonal occurrence and site fidelity of juvenile bronze whalers (Carcharhinus brachyurus) in a temperate inverse estuary. Mar. Biol. 166, 1-17.

Dudley, S. F., and Cliff, G. (2010). Influence of the annual sardine run on catches of large sharks in the protective gillnets off KwaZulu-Natal, South Africa, and the occurrence of sardine in shark diet. Afr. J. Mar. Sci. 32, 383-397. doi: $10.2989 / 1814232 \times .2010 .502641$

Espinoza, M., Heupel, M. R., Tobin, A. J., and Simpfendorfer, C. A. (2016). Evidence of partial migration in a large coastal predator: opportunistic foraging and reproduction as key drivers? PLoS One 11:e0147608. doi: 10.1371/journal. pone. 0147608

Geraghty, P. T., Williamson, J. E., Macbeth, W. G., Blower, D. C., Morgan, J. A., Johnson, G., et al. (2014). Genetic structure and diversity of two highly vulnerable carcharhinids in Australian waters. Endang. Species Res. 24, 45-60. doi: $10.3354 /$ esr00580

Gu, Z., Gu, L., Eils, R., Schlesner, M., and Brors, B. (2014). circlize implements and enhances circular visualization in R. Bioinformatics 30, 2811-2812. doi: 10.1093/bioinformatics/btu393

Heupel, M. R., Simpfendorfer, C. A., Espinoza, M., Smoothey, A. F., Tobin, A., and Peddemors, V. (2015). Conservation challenges of sharks with continental scale migrations. Front. Mar. Sci. 2:12. doi: doi: 10.3389/fmars.2015.00012

Hoenner, X., Huveneers, C., Steckenreuter, A., Simpfendorfer, C., Tattersall, K., Jaine, F., et al. (2018). Australia's continental-scale acoustic tracking database and its automated quality control process. Sci. Data 5:170206. doi: 10.1038/ sdata.2017.206

Hoffmayer, E. R., Franks, J. S., Driggers, W. B., McKinney, J. A., Hendon, J. M., and Quattro, J. M. (2014). Habitat, movements and environmental preferences of dusky sharks. Carcharhinus obscurus, in the northern Gulf of Mexico. Mar. Biol. 161, 911-924. doi: 10.1007/s00227-014-2391-0

Hussey, N. E., Kessel, S. T., Aarestrup, K., Cooke, S. J., Cowley, P. D., Fisk, A. T., et al. (2015). Aquatic animal telemetry: A panoramic window into the underwater world. Science 348:1255642. doi: 10.1126/science. 1255642

Hussey, N., McCarthy, I., Dudley, S. F. J., and Mann, B. (2009). Nursery grounds, movement patterns and growth rates of dusky sharks. Carcharhinus obscurus: a long-term tag and release study in South African waters. Mar. Freshwater Res. 60, 571-583. doi: $10.1071 / \mathrm{mf0} 280$

Huveneers, C., Jaine, F. R. A., Barnett, A., Butcher, P. A., Clarke, T. M., CurreyRandall, L. M., et al. (2021). The power of national acoustic tracking networks to assess the impacts of human activity on marine organisms during the COVID-19 pandemic. Biol. Conservat. 2021:108995. doi: 10.1016/j.biocon.2021. 108995

Huveneers, C., Rigby, C. L., Dicken, M., Pacoureau, N., and Derrick, D. (2020). Carcharhinus brachyurus. The IUCN Red List of Threatened Species e.T41741A2954522. Gland: International Union for Conservation of Nature, doi: 10.2305/IUCN.UK.2020-3.RLTS.T41741A2954522.en

Huveneers, C., Simpfendorfer, C. A., Kim, S., Semmens, J. M., Hobday, A. J., Pederson, H., et al. (2016). The influence of environmental parameters on the performance and detection range of acoustic receivers. Methods Ecol. Evol. 7, 825-835. doi: 10.1111/2041-210x.12520

Izzo, C., Huveneers, C., Drew, M., Bradshaw, C. J., Donnellan, S. C., and Gillanders, B. M. (2016). Vertebral chemistry demonstrates movement and population structure of bronze whaler. Mar. Ecol. Prog. Series 556, 195-207. doi: 10.3354/ meps 11840

Junge, C., Donnellan, S. C., Huveneers, C., Bradshaw, C. J., Simon, A., Drew, M., et al. (2019). Comparative population genomics confirms little population structure in two commercially targeted carcharhinid sharks. Mar. Biol. 166:16.

Kerr, L. A., Hintzen, N. T., Cadrin, S. X., Clausen, L. W., Dickey-Collas, M., Goethel, D. R., et al. (2016). Lessons learned from practical approaches to reconcile mismatches between biological population structure and stock units of marine fish. ICES J. Mar. Sci. 74, 1708-1722. doi: 10.1093/icesjms/ fsw188
Kessel, S., Cooke, S., Heupel, M., Hussey, N., Simpfendorfer, C., Vagle, S., et al. (2014). A review of detection range testing in aquatic passive acoustic telemetry studies. Rev. Fish Biol. Fish. 24, 199-218. doi: 10.1007/s11160-013-9328-4

Kohler, N., Casey, J. G., and Turner, P. A. (1998). NMFS cooperative shark tagging programme, 1962-93: An atlas of shark tag and recapture data. Mar. Fish. Rev. 60, 1-87. doi: 10.7755/mfr.81.2.1

Lascelles, B., Notarbartolo Di Sciara, G., Agardy, T., Cuttelod, A., Eckert, S., Glowka, L., et al. (2014). Migratory marine species: their status, threats and conservation management needs. Aquat. Conserv. 24, 111-127. doi: 10.1002/ aqc. 2512

Last, P. R., and Stevens, J. D. (2009). Sharks and rays of Australia. Australia: CSIRO Australia.

Lédée, E., Heupel, M., Taylor, M., Harcourt, R., Fabrice, J., Huveneers, C., et al. (2021). National-scale acoustic telemetry and network analysis reveal new insights into stock structure. Fish Fisheries. faf.12565.

Lowe, W. H., and Allendorf, F. W. (2010). What can genetics tell us about population connectivity? Mole. Ecol. 19, 3038-3051. doi: 10.1111/j.1365-294x. 2010.04688.x

Lucifora, L. O., Menni, R. C., and Escalante, A. H. (2005). Reproduction and seasonal occurrence of the copper shark, Carcharhinus brachyurus, from north Patagonia, Argentina. ICES J. Mar. Sci. 62, 107-115. doi: 10.1016/j.icesjms. 2004.09.003

Macbeth, W., Geraghty, P., Peddemors, V. M., and Gray, C. (2009). Observer-based study of targeted commercial fishing for large shark species in waters off northern New South Wales. Australia: Final report to the Northern Rivers Catchment Management Authority.

McAuley, R. B., Simpfendorfer, C. A., and Hall, N. G. (2007). A method for evaluating the impacts of fishing mortality and stochastic influences on the demography of two long-lived shark stocks. ICES J. Mar. Sci. 64, 1710-1722. doi: 10.1093/icesjms/fsm146

McAuley, R., Bruce, B., Keay, I., Mountford, S., Pinnell, T., and Whoriskey, F. (2017). Broad-scale coastal movements of white sharks off Western Australia described by passive acoustic telemetry data. Mar. Freshwater Res. 68, 15181531. doi: $10.1071 / \mathrm{mf} 16222$

McMillan, M., Huveneers, C., Semmens, J., and Gillanders, B. (2018). Natural tags reveal populations of Conservation Dependent school shark use different pupping areas. Mar. Ecol. Prog. Series 599, 147-156. doi: 10.3354/meps 12626

Nevatte, R. J., Williamson, J. E., Wueringer, B. E., and Gillings, M. R. (2021). Contrasting patterns of population structure in commercially fished sawsharks from southern Australian waters. Rev. Fish Biol. Fish. 2021, 1-21.

O’Dor, R. K., and Stokesbury, M. J. (2009). “The Ocean Tracking Network-Adding Marine Animal Movements to the Global Ocean Observing System," in Tagging and Tracking of Marine Animals with Electronic Devices, eds J. L. Nielsen, H. Arrizabalaga, N. Fragoso, A. Hobday, M. Lutcavage, and J. Sibert (Berlin: Springer), 91-100. doi: 10.1007/978-1-4020-9640-2_6

Ovenden, J. R. (2013). Crinkles in connectivity: combining genetics and other types of biological data to estimate movement and interbreeding between populations. Mar. Freshwater Res. 64, 201-207. doi: 10.1071/mf12314

Ovenden, J. R., Kashiwagi, T., Broderick, D., Giles, J., and Salini, J. (2009). The extent of population genetic subdivision differs among four co-distributed shark species in the Indo-Australian archipelago. BMC Evol. Biol. 9, 1-15. doi: 10.1186/1471-2148-9-40

Pacoureau, N., Rigby, C. L., Kyne, P. M., Sherley, R. B., Winker, H., Carlson, J. K., et al. (2021). Half a century of global decline in oceanic sharks and rays. Nature 589, 567-571. doi: 10.1038/s41586-020-03173-9

Petrusevics, P. (1993). SST fronts in inverse estuaries, South Australia-indicators of reduced gulf-shlef exchange. Mar. Freshwater Res. 44, 305-323. doi: 10.1071/ mf 9930305

Pincock, D. (2008). False Detections: What They Are and How to Remove Them from Detection Data. DOC-004691 Version 01.

Pleizier, N., Gutowsky, L. F., Peddemors, V. M., Cooke, S. J., and Butcher, P. A. (2015). Variation in whole-, landed-and trimmed-carcass and fin-weight ratios for various sharks captured on demersal set-lines off eastern Australia. Fish. Res. 167, 190-198. doi: 10.1016/j.fishres.2015.02.008

Rigby, C. L., Barreto, R., Carlson, J., Fernando, D., Fordham, S., Francis, M. P., et al. (2019). Carcharhinus obscurus. The IUCN Red List of 
Threatened Species e.T3852A2872747. Available online at: https://dx.doi.org/10. 2305/IUCN.UK.2019-3.RLTS.T3852A2872747.en (accessed date:28 September 2020).

Rogers, P., Braccini, M., Peddemors, P., Roelofs, A., and Woodhams, J. (2021). "Bronze whaler, Carcharhinus brachyurus," in Status of Australian fish stocks reports 2020, eds T. Piddocke, C. Ashby, K. Hartmann, A. Hesp, P. Hone, J. Klemke, et al. (Canberra: Fisheries Research and Development Corporation).

Rogers, P., Huveneers, C., Goldsworthy, S. D., Cheung, W. W. L., Jones, K. G., Mitchell, J. G., et al. (2013a). Population metrics and movement of two sympatric carcharhinids: a comparison of the vulnerability of pelagic sharks of the southern Australian gulfs and shelves. Mar. Freshwater Res. 64, 20-30. doi: $10.1071 / \mathrm{mf1} 1234$

Rogers, P., Huveneers, C., Goldsworthy, S. D., Mitchell, J. G., and Seuront, L. (2013b). Broad-scale movements and pelagic habitat of the dusky shark Carcharhinus obscurus off Southern Australia determined using pop-up satellite archival tags. Fish. Oceanogr. 22, 102-112. doi: 10.1111/fog.12009

Romine, J. G., Musick, J. A., and Burgess, G. H. (2009). Demographic analyses of the dusky shark, Carcharhinus obscurus, in the Northwest Atlantic incorporating hooking mortality estimates and revised reproductive parameters. Env. Biol. Fish. 84, 277-289. doi: 10.1007/s10641-008-9435-6

Simpfendorfer, C. A. (1999). Demographic analysis of the dusky shark fishery in Southwestern Australia. Am. Fish. Soc. Symp. 23, 149-160.

Simpfendorfer, C. A., Huveneers, C., Steckenreuter, A., Tattersall, K., Hoenner, X., Harcourt, R., et al. (2015). Ghosts in the data: false detections in VEMCO pulse position modulation acoustic telemetry monitoring equipment. Animal Biotelemet. 3:1.

Steckenreuter, A., Hoenner, X., Huveneers, C., Simpfendorfer, C., Buscot, M. J., Tattersall, K., et al. (2017). Optimising the design of large-scale acoustic telemetry curtains. Mar. Freshwat. Res. 68, 1403-1413. doi: 10.1071/ MF16126

Steer, M., Fowler, A., Rogers, P., Bailleul, F., Earl, J., Matthews, D., et al. (2020). Assessment of the South Australian Marine Scalefish Fishery in 2018. SARDI
Publication No. F2017/000427-3. SARDI Research Report Series No. 1049. South Australia: SARDI Aquatics Sciences.

Turan, C. (2004). Stock identification of Mediterranean horse mackerel (Trachurus mediterraneus) using morphometric and meristic characters. ICES J. Mar. Sci. $61,774-781$.

Waples, R. S., Punt, A. E., and Cope, J. M. (2008). Integrating genetic data into management of marine resources: how can we do it better? Fish Fisheries 9, 423-449.

Waters, J. M. (2008). Marine biogeographical disjunction in temperate Australia: historical landbridge, contemporary currents, or both? Diver. Distrib. 14, 692700 .

Wood, S., and Wood, M. S. (2015). Package 'mgcv'. R package version, Vol. 1:29.

Woodhams, J., Braccini, M., Peddemors, P., and Rogers, P. (2021). Dusky shark, Carcharhinus obscurus," in Status of Australian fish stocks reports 2020. Canberra: Fisheries Research and Development Corporation.

Conflict of Interest: The authors declare that the research was conducted in the absence of any commercial or financial relationships that could be construed as a potential conflict of interest.

Publisher's Note: All claims expressed in this article are solely those of the authors and do not necessarily represent those of their affiliated organizations, or those of the publisher, the editors and the reviewers. Any product that may be evaluated in this article, or claim that may be made by its manufacturer, is not guaranteed or endorsed by the publisher.

Copyright $\odot 2021$ Huveneers, Niella, Drew, McAuley, Butcher, Peddemors, Waltrick, Dowling, Mountford, Keay and Braccini. This is an open-access article distributed under the terms of the Creative Commons Attribution License (CC BY). The use, distribution or reproduction in other forums is permitted, provided the original author(s) and the copyright owner(s) are credited and that the original publication in this journal is cited, in accordance with accepted academic practice. No use, distribution or reproduction is permitted which does not comply with these terms. 